\title{
Embroidery patterns of the Qing Dynasty robes
}

Chi-Shyong Tzeng / Yu-Fu Chen / Shyh-Bao Chiang / National Yunlin University of Science and Technology / Yunlin / Taiwan

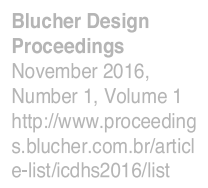

\begin{abstract}
In the Qing Dynasty robes pattern on a sample cut from the visual design point of view, through field surveys, comparative Induce Act, comparison, analysis of the structure and pattern shape characteristics. The results found that, in the Qing Dynasty robes and line pattern is formed with a very close association. Having a form of class 3 , the dotted line, cross, curve, by way of permutations and combinations, and evolved into the broken line side by side, mesh, ring. Dashed lines the most common pattern consisting of relatively simple, the use of a larger number. Patterns constitute a cross shape is more complex, a fixed usage patterns. Arc, constitute a more flexible pattern often used on a wide range of image composition. Line is an extension application constitutes the basis of the design of the study, the traditional design thinking, utilizing modern design practice.
\end{abstract}

\section{Keywords}

Pattern, shape, line configuration, the Qing Dynasty robes

\section{Research Purpose}

The late Qing feudal nation, as the demand of the ruling class, as well as harassment in the form of clothing, apparel developed rapidly. Through apparel production process, access to a variety of semantic patterns containing as cultural symbols, giving a deeper symbolic meaning. Among them, the figurative form the main element unit again form constituted, composed of diverse complex shape features. In the Qing Dynasty robes as samples from a visual design perspective, the analysis of the structure of clothing pattern shape, providing an image as a study of the Qing Dynasty culture foundation. National Museum of History is a collection of many in Taiwan in the Qing Dynasty robes cultural relics units, taking into consideration the objectivity of the study sample, therefore, to the museum's collection items as research subjects. Museum of History and storage application, conduct field surveys Qing Dynasty costumes. Robes survey sample 17 for analysis at this stage in the Qing Dynasty embroidery pattern biography.

\section{Research Sample}

Using a field survey of the way by the real ancient relics image capture, view it through with the National Palace Museum collection of data, and image form books mentioned. The 17 encodes the Qing Dynasty robes, and performed sample analysis. Analysis of samples, use the inductive method for image comparison compare the sample pattern, conducted sampling pattern is depicted. Due to complex forms, interleaved, and therefore among the parts of the pattern to capture as artwork depicting, for analysis purposes. And supplemented Museum collection image data, and image books, understood as a pattern, comparative information. From the stage of the research process, only constitute a pattern shape analysis, visual angle from the plane to explore the structure and pattern of cell morpholo-
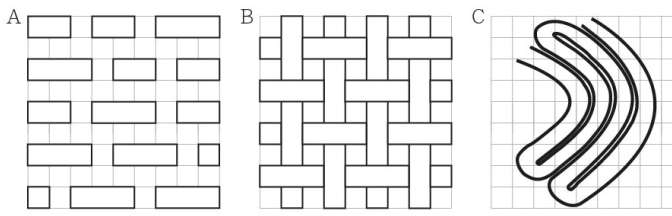

Fig. 1: Embroidery unit pictures. (Produced by the researcher) gy. Study samples 17, 25 pen pattern. After sampling the image to compare the research method mutual comparison, according to the basic pattern shape manner, divided into $A, B, C$ three kinds (Figure 1).

A class pattern to form a broken line as a unit composed patterns, each dotted line are parallel. On a Class B pattern, weft way interaction into a cross-shaped cell morphology. Class $\mathrm{C}$ 
main pattern in an arc, line to arc pathway, wrap, stick together, so that the line gradually aligned surface. Cell structure pattern three were dashed line, cross, arcs, and then a combination of the broken line side by side, mesh, ring-shaped image. According to three Patterns, samples were classified.

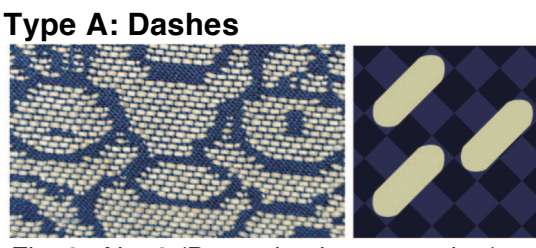

Fig. 2: No. 2 (Drawn by the researcher)

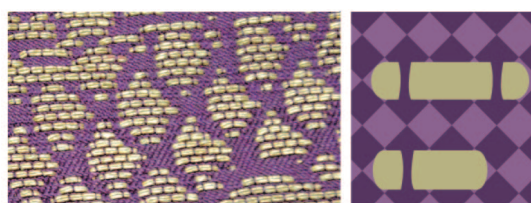

Fig. 4: No. 5 (Drawn by the researcher)

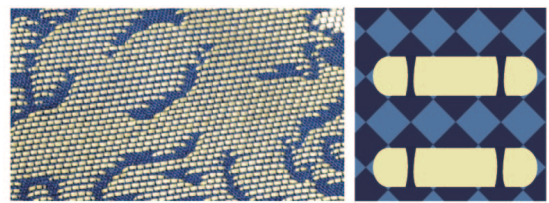

Fig. 6: No. 9 (Drawn by the researcher)

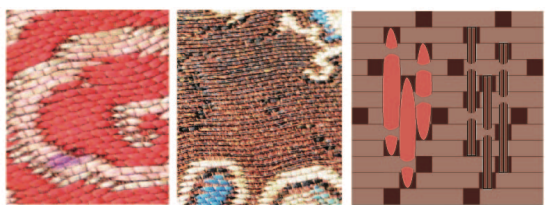

Fig. 8: No. 6a, b (Drawn by the researcher)

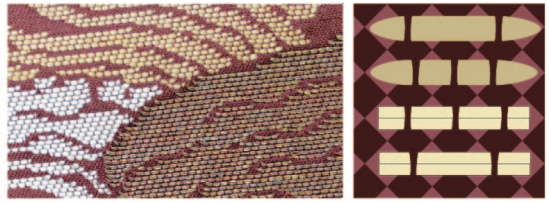

Fig. 10: No. 11a, b (Drawn by the researcher)
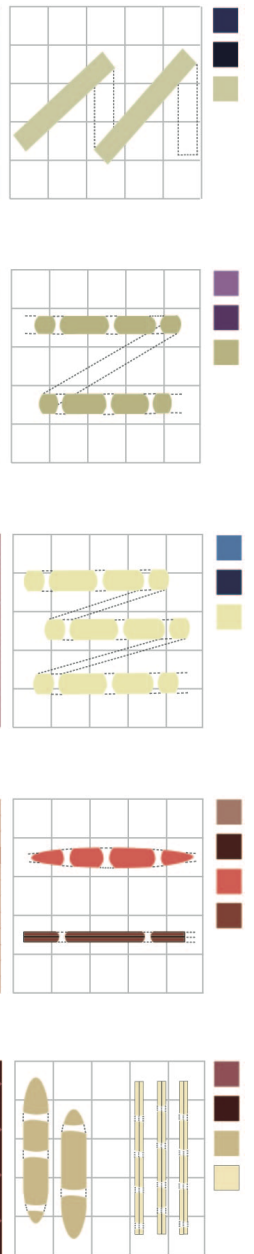

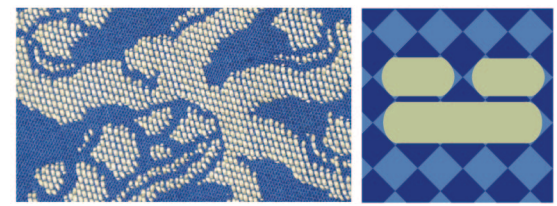

Fig. 3: No. 3 (Drawn by the researcher)

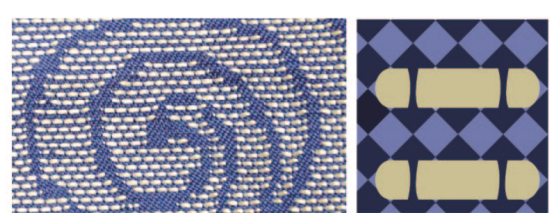

Fig. 5: No. 7 (Drawn by the researcher)

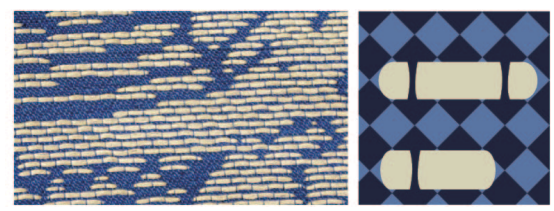

Fig. 7: No. 14 (Drawn by the researcher)
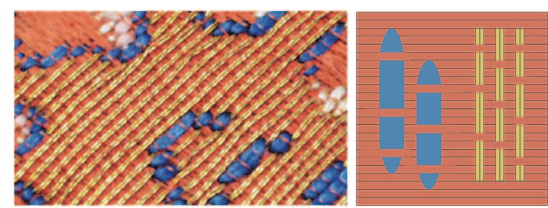

Fig. 9: No. 10a, b (Drawn by the researcher)

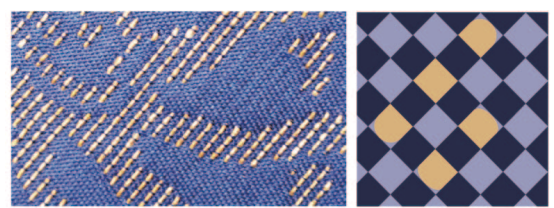

Fig. 11: No. 4 (Drew by the research)
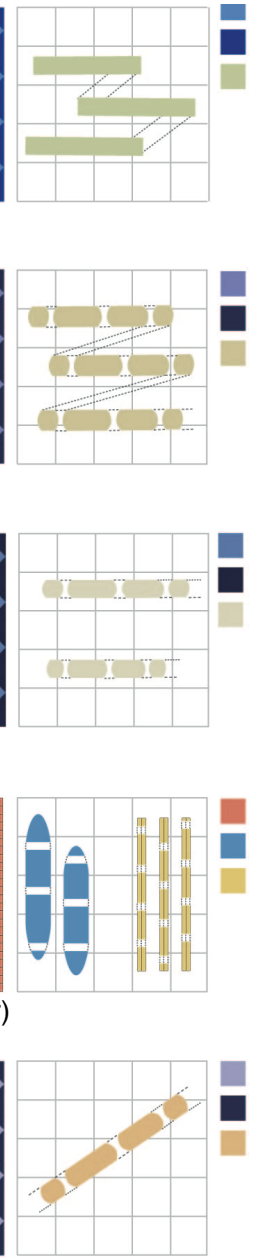

\section{Type B - Cross}

There are four strokes (12-14), it can be divided into two modes. The first one kind of coarse weft, warp smaller, less obvious cross-shaped cell morphology. The second type, the cross section shape of the more obvious, and aggregated into a mesh.
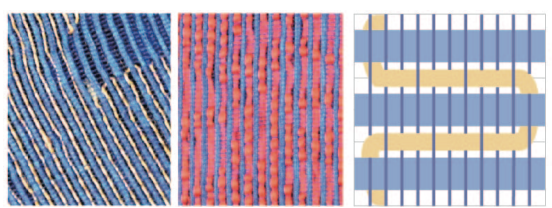

Fig.12: No. 1a, b (Drawn by the researcher)

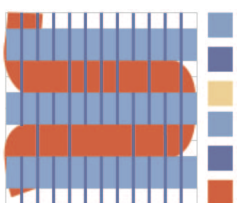

4 II

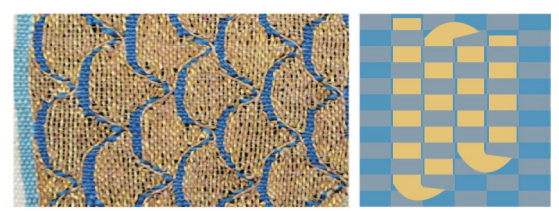

Fig. 14: No. 13 (Drawn by the researcher)

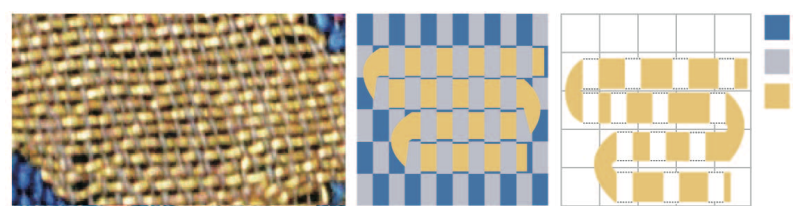

Fig. 13: No. 8 (Drawn by the researcher) 


\section{Type C - Arc}

4 data (Figure15-18), contain Class A pattern combined with each other. Line path parallel to the main arc, snapping, rewind, constitute a ring. Minimal gap between line and line, line and line in flush manner, so that wound into the surface region. More particularly, for the construction of a wider region to form a surface image.

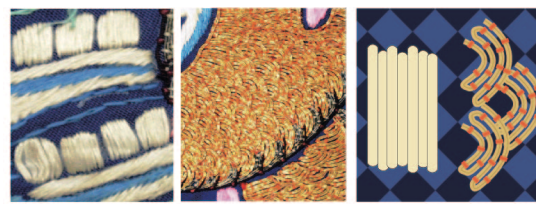

Fig. 15: No. 12 (Drawn by the researcher)

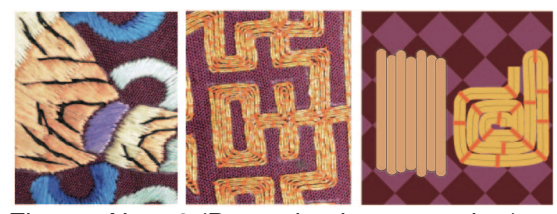

Fig. 17: No. 16 (Drawn by the researcher)
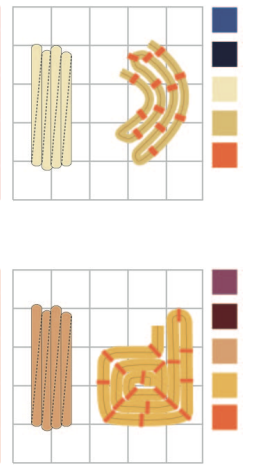

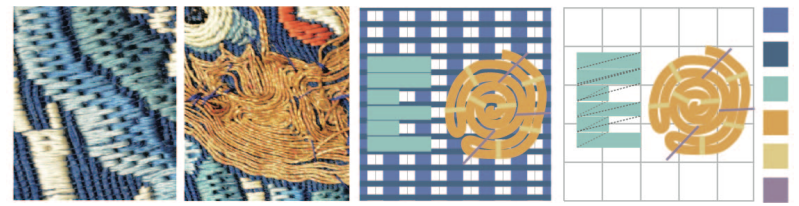

Fig. 16: No. 15 (Drawn by the researcher)

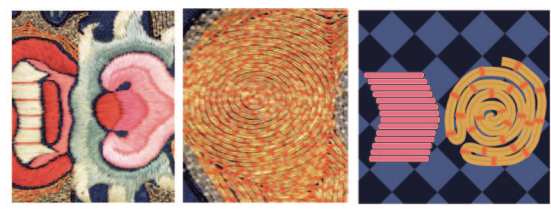

Fig. 18: No. 17 (Drawn by the researcher)

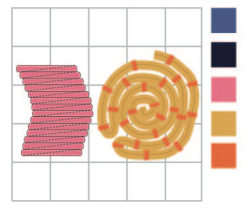

\section{Research Conclusion}

The traditional patterns of the Qing Dynasty costumes to basic design principles shape cut from three basic elements form the pattern, A Class dashed Cross Class B, Class C arc for the initial constitution of the Qing Dynasty Costume Designs, approximate the results demonstrate the basic discussion. Graphic design from the perspective of the Qing Dynasty robes pattern shape, though are in line as the basis for the composition, but also contains the basic principles constitute the dotted line, crosshairs, arcs and other images. By way of permutation and combination, side by side to form a mesh, ring and other composite image. Patterns of the Qing Dynasty costumes, it can be said that the practical application of the principles of modern basic shape. Through a preliminary analysis of this study to examine the context of the evolution of the traditional pattern, hoping to crystallize the ancients thought of the past, cultural background into the design thinking of them, provide the basis for the application holds many lessons for graphic design.

\section{References}

Huang NF and Chen JJ (1999) Chinese Clothing Arts in Past Dynasties. Beijing: China Travel. Li Y(1997) Ancient Chinese Embroidery Art. Taipei: SMC Publishing Inc.

The National Museum of History (1998) The Universe of Silk Embroidery. Taipei: The National Museum of History.

The National Museum of History (2000) Beauty and Auspice. Taipei: The National Museum of History.

T, W. E. (2009) The Embroidery World. Taipei: Long-Gang Digital.

Nian, BH (2003) One Hundred Embroidery Techniques. Taipei: Lion Books.

Wu M (2009) Embroidery. Taipei: Youth.

Wang, JY (2000) Taiwanese Folk Embroidery. Taipei: Shan-Zhou Editor.

Wu ZY and Huang XY (2009) Word Origin. Taipei: The Commercial Press, Ltd.

Yang L (2009) Embroidery of Ming and Qing. Taipei: Arts Library.

Zhu PC (2009) Chinese Embroidery. Taipei: Lion Books. 